\title{
Os Conselhos Gestores de Políticas Públicas: espaços de consolidação da administração pública societal?
}

The Management Councils for Public Policy: spaces of consolidation of public administration?

Los Consejos Gestores de Políticas Públicas: espacios de consolidación de la administración pública societal?

João André Nascimento Ribas Mestrado em Planejamento e Governança Pública, Universidade Tecnológica Federal do Paraná Tutor no curso de Bacharel em Administração Pública, Universidade Estadual de Ponta Grossa http://lattes.cnpq.br/9189159171968264 https://orcid.org/0000-0002-5653-754X

joaoribas@alunos.utfpr.edu.br

Maria Lucia Figueiredo Gomes de Meza Doutorado/ UFPR - Desenvolvimento Econômico Professora da Universidade Tecnológica Federal do Paraná http://lattes.cnpq.br/3634990002513047 https://orcid.org/0000-0002-1875-5140 malumeza@utfpr.edu.br

Resumo: A administração pública gerencial adotada no Brasil na década de 1990, aliada ao neoliberalismo, resultou em avanços insuficientes das políticas socioeconômicas e em centralismo decisório sobre a vida pública. Por isto, reacenderam-se discussões sobre um modelo ideal de administração, que se traduziram em experiências como as dos conselhos gestores de políticas públicas, com intuito de delinear um desenho institucional de partilha de poder assente na administração societal. Entretanto, dada a continuidade dos pressupostos gerenciais no país, faz-se pertinente analisar se tais conselhos têm se efetivado como práticas da administração societal. Por meio de uma pesquisa qualitativa e descritiva, levantou-se que tais colegiados, enquanto compostos pelas disfunções apresentadas, servem mais como instrumento de gerencialismo do que como consolidação do modelo societal. Por isso, aponta-se que as disfunções dos conselhos gestores podem ser solucionadas sob a luz da burocracia weberiana e da cidadania republicana para se consolidarem como modelo de administração societal.

Palavras-Chave: Administração Societal Conselhos Gestores; Participação Social, Sociedade Civil.

\begin{abstract}
Managerial public administration adopted in Brazil in the 1990s, combined with neoliberalism, has resulted in the insufficient progress of socioeconomic policies and in the centralization of decision-making about public life. Therefore, discussions were reopened on the subject of an ideal model of administration, which resulted in experiences such as the management councils of public policy, in order to outline an institutional design of power-sharing based on societal administration. However, given the continuity of management assumptions in the country, it is relevant to examine whether such councils have become a reality as practices of societal management. Conducting a descriptive and qualitative research, it was observed that such boards, while composed by the presented dysfunctions, are a management instrument more than a consolidation of the societal model. Therefore, it was noted that the dysfunctions of the management councils can be solved in the light of the Weberian bureaucracy and republican citizenship so they can be consolidated as a model of societal management.
\end{abstract}

Keywords: Societal Administration; Management Councils; Social Participation, Civil Society.

Resumen: La administración pública gerencial adoptada en Brasil en la década de 1990, aliada al neoliberalismo, resultó en avances insuficientes de las políticas socioeconómicas y en el centralismo decisorio sobre la vida pública. Por eso, se reanudaron discusiones sobre un modelo ideal de administración, que se tradujeron en experiencias como las de los consejos gestores de políticas públicas, con el fin de delinear un diseño institucional de reparto de poder basado en la administración societal. Sin embargo, dada la continuidad de los presupuestos gerenciales en el país, se hace pertinente analizar si tales consejos se han efectuado como prácticas de la administración societal. Por medio de una investigación cualitativa y descriptiva, se levantó que tales colegiados, como compuestos por las disfunciones presentadas, sirven más como instrumento de gerencialismo que como consolidación del modelo societal. Por eso, se nota que las disfunciones de los consejos gestores pueden ser solucionadas através de la burocracia weberiana y de la ciudadanía republicana para consolidarse como modelo de administración societal.

Palabras clave: Administración Societal Consejo de Administración; Participación Social, Sociedad Civil.

Texto completo em português: http://www.apgs.ufv.br Full text in Portuguese: http://www.apgs.ufv.br

\section{Introdução}

A Administração Pública brasileira passou a mesclar características dos modelos patrimonialista e burocrático, posteriormente à primeira reforma de Estado implantada por Getúlio Vargas, em 1936. Mais tarde, no decorrer da década de 1990, na busca da maximização da eficiência pública, com a segunda reforma adotada por Fernando Henrique Cardoso - FHC, a Administração Pública gerencial consolidou-se como modelo ideal. Sem, porém, desvincular-se das raízes dos modelos antecedentes. Aliado ao neoliberalismo, o gerencialismo reconfigurou o Estado brasileiro de acordo com políticas internacionais advindas dos países economicamente majoritários e de suas corporações privadas. Nesse contexto, um dos principais motivos da má gestão interna a respeito de políticas econômicas e sociais passou a ser o insuficiente avanço da democracia ${ }^{1}$, o qual condiciona os serviços do Estado aos interesses de grupos específicos..

Devido aos insucessos de desenvolvimento econômico e ao centralismo decisório sobre a vida política do país, advindos posteriormente à reforma de Estado pelo gerencialismo aliado aos princípios neoliberais, reacenderam-se debates sobre ascensão de um modelo ideal de Administração Pública. Assim, ao longo da década de 1990 e do começo do novo século, estudos sobre práticas de modelos alternativos receberam destaque por pesquisadores sociais para se visionar estratégias sobre como envolver a sociedade civil na busca de soluções para os problemas públicos, como por intermédio da Administração Societal. 
A Administração Societal se apresentou como alternativa ao modelo gerencial, apresentando a possibilidade de envolver a ampla sociedade no debate sobre políticas públicas com base nos problemas advindos da população. Esta busca colocar em prática o conceito republicano de cidadania, na construção de sujeitos políticos participativos, capazes de atuarem junto aos governantes no direcionamento do Estado. No entanto, ofuscada pelo modelo gerencial, que seguia recomendações de organismos multilaterais internacionais e centralizava o processo decisório nos Poderes Públicos, não ascendeu como reforma de Estado, embora seja implementada de forma dispersa nos entes federativos.

O modelo institucional democrático, priorizado no Brasil, com o modelo gerencial foi o de democracia representativa, passível de contestação com relação ao distanciamento entre eleitores e eleitos, sobrepondo o desenvolvimento do modelo de democracia participativa assente nos anos de 1960 (GONZALEZ, 2011). Hirst (1992) aponta que a democracia representativa possui como problema a pouca participação popular nas decisões políticas e na prestação de contas à sociedade. Tanto que a conjuntura atual demonstra que os cidadãos mantêm uma relativa frustração com a política e com a Administração Pública, sobretudo, a respeito da corrupção, patrimonialismo e ineficiência, não solucionados pela Administração Pública gerencial. Tais pontos trazem uma descrença universal na gestão pública e nos representantes eleitos democraticamente. Por isso, faz-se necessário promover uma democracia mais participativa, visto que a atuação política dos cidadãos se limita comumente no sufrágio universal.

Fernández (2010) afirma que os cidadãos deixaram de confiar nas formas tradicionais de participação política demandando uma relação mais direta com a gestão pública, colocando em voga a metodologia democrática propagada pelo modelo neoliberal. Da mesma forma, outros autores contemporâneos influentes destacam a importância da participação social nas decisões públicas, como Jürgen Habermas, Norberto Bobbio e Boaventura de Souza Santos. Assim, partindo de um estudo sobre experiências internacionais de participação, o informe do Comitê de Ministros do Conselho da Europa (2001, apud FERNÁNDEZ, 2010, p. 23) destaca a importância do desenvolvimento dos seguintes pontos: "a) novos instrumentos que vinculem a participação a processos de tomada de decisões; b) instrumentos que implementem formas mais flexíveis de participação; e c) instrumento que incluam a população não organizada".

Nesse contexto, as principais experiências participativas atuais, no Brasil, que buscam efetivar os apontamentos do Comitê são dadas pelo desenvolvimento dos Conselhos Gestores de Políticas Públicas, com raízes em práticas na área de saúde, antecedentes à Constituição Federativa de 1988, e pelo orçamento participativo desenvolvido no governo municipal de Porto Alegre, em 1989, sob gestão do Partido dos Trabalhadores - PT, o qual se ampliou nacionalmente e internacionalmente. Posteriormente à Constituição Federativa de 1988, a qual incentiva a participação social, de modo disperso, com destaque aos artigos 198 e 204, houve a consolidação legal dos Conselhos Gestores, com intuito de se delinear um desenho institucional de partilha de poder entre sociedade civil e governos. Assim, dadas as diversas pesquisas sobre a implementação destes colegiados, como instâncias de decisões sobre Políticas Públicas, durante as décadas de 1990 e 2000, formula-se o questionamento: os Conselhos Gestores Municipais podem ser apontados como práticas efetivas da Administração Pública Societal, de forma a idealizar tal modelo administrativo para o país?

Por isso, o objetivo deste artigo é de analisar se os Conselhos Gestores Municipais de Políticas Públicas têm se consolidado como modelos de Administração Pública Societal no Brasil. Para isso, realizar-se-á um ensaio teórico qualitativo e descritivo, alinhando estudos desenvolvidos por outros pesquisadores sobre as práticas dos Conselhos Gestores. Após esta introdução, o artigo apresenta na parte dois os modelos de Administração Pública adotados no país, com destaque ao gerencial e ao societal. Já a parte três trata da participação social e da conceituação de cidadania e de conselhos, com foco nos gestores de políticas públicas. A parte quatro apresenta uma síntese de pesquisas sobre a organização dos Conselhos Gestores pelo Brasil, com base em autores referências no tema, para finalmente concluir mediante considerações a respeito do avanço da prática da Administração Pública Societal e sugestões para pesquisas futuras.

\section{Modelos de Administração Pública: Gerencial e Societal}

O debate sobre participação social no Brasil ocorreu, concomitantemente, à busca de um modelo ideal de Administração Pública, ao longo do século XX e início do século XXI. Sob embasamento weberiano de burocracia, o primeiro governo de Getúlio Vargas realiza uma reforma de Estado com vistas a desvencilhar a Administração Pública das características patrimonialistas e avançar no desenvolvimento econômico. No entanto, a burocracia não conquistou plena independência do patrimonialismo durante o Regime Militar, iniciado nos anos de 1960, quando houve a passagem do controle oligárquico para o tecnoburocrático. Nas palavras de Bresser-Pereira (1977), a "evolução histórica do Estado brasileiro, o qual, sempre conservando seu caráter essencialmente capitalista, evolui do controle oligárquico agrário-mercantil para 0 controle tecnoburocrático, passando por uma fase intermediária populista".

Durante a segunda metade do século $\mathrm{XX}$, a Administração Societal e a Administração Gerencial conquistaram espaços empíricos na Gestão Pública, sob diferentes perspectivas. Enquanto que o modelo societal adveio das mobilizações sociais por reformas no país, nos anos de 1960, perdendo forças com a ascensão dos militares ao Poder Executivo, em 1964, o modelo gerencial foi desenvolvido no Brasil ao longo dos anos de 1990, posteriormente à redemocratização, na busca de se trazer maior eficiência e credibilidade ao Estado, então em crise nacionaldesenvolvimentista (PAES-PAULA, 2005).

Para Bresser-Pereira (1996), a reforma da Administração Pública Gerencial pode ser reconhecida como a segunda desenvolvida no país, considerando como primeira a burocrática. $\mathrm{O}$ 
autor aponta a crise da Administração Pública Burocrática como causa de um período de estagnação econômica e de alta inflação no início dos anos de 1990. Incapaz de extirpar o patrimonialismo, com contratações de administradores empresariais no decorrer do Regime Militar, sua aplicabilidade se demonstrou como: "lenta, cara, auto-referida, pouco ou nada orientada para o atendimento das demandas dos cidadãos" (BRESSER-PEREIRA, 1996, p. 5).

A vertente da Administração Pública Gerencial tem como berço o governo de Margareth Thatcher, no Reino Unido, e de Ronald Reagan, nos Estados Unidos. Por meio de pressupostos empreendedores, objetiva orientar atividades públicas com maior eficiência e produtividade, pela reforma do aparelho do Estado (PAES-PAULA, 2005). Contudo, Bresser-Pereira (1996) relata que a ideia deste modelo no Brasil é antiga, aplicado nos anos de 1930, com a criação da primeira autarquia, e no Regime Militar, com o Programa Nacional de Desburocratização, lançado em 1979. Entretanto, a consolidação da Administração Pública Gerencial deuse no governo $\mathrm{FHC}$, por meio de um consenso político liberal e dependente e pela reforma de Estado, arquitetada pelo então ministro Luiz Carlos Bresser-Pereira, para combater a crise fiscal e a intervenção do Estado na economia. A principal característica desta reforma era a adoção de princípios do gerencialismo privado adaptado ao setor público. Aliado às políticas neoliberais, o modelo acarretou na redução do papel do Estado na globalização do capital.

Embora a Administração Societal não tenha conquistado o seu momento de consolidação reformista, esteve ligada às mobilizações dos anos de 1960, que buscavam reformas de Estado, e de grupos ao longo dos anos de 1970, que lutaram por direito à cidadania. Sua prática nos anos de 1980 ocorre por meio das reinvindicações à democracia, cidadania e fortalecimento da participação da sociedade civil na política do país, tendo garantido princípios democráticos e de participação social no texto da Constituição de 1988. Dentre as reinvindicações populares, durante a elaboração da nova Constituição, o Movimento Nacional pela Reforma Urbana apresentou à Assembleia Nacional Constituinte uma proposta que envolveu o pedido de participação social nas decisões urbanas e de direito à cidade (AVRITZER, 2008).

Resumindo, enquanto que na Administração Gerencial há a imposição do Estado sobre a sociedade, a Administração Pública Societal objetiva:

[...] substituir a gestão tecnoburocrática por um gerenciamento mais participativo, dialógico, no qual o processo decisório é exercido por meio de diferentes sujeitos sociais. [...] Portanto, no contexto da gestão social orientada pela racionalidade comunicativa, os atores, ao fazerem as suas apostas, não podem impor suas pretensões de validade sem que haja um acordo alcançado comunicativamente no qual todos os participantes exponham suas argumentações (TENÓRIO, 1998, p. 16).

Mesmo considerando que a Administração Gerencial enfoca as dimensões econômica e financeira e a institucional-administrativa, enquanto que a Administração Societal considera a dimensão sociopolítica (PAES-PAULA, 2005), ou seja, as relações entre o Estado e a sociedade em ambos os modelos se posicionam como ampliadores da democracia. Como se percebe nas palavras de
Bresser-Pereira (1996, p. 17), o objetivo da reforma de Estado gerencial seria: "a curto prazo, facilitar o ajuste fiscal, particularmente nos Estados e municípios, onde existe um claro problema de excesso de quadros; a médio prazo, tornar mais eficiente e moderna a administração pública, voltando-a para o atendimento dos cidadãos". Com a ampliação da esfera pública não-estatal, mediante as organizações sociais, o autor enfatizava a possibilidade de se ampliar o caráter democrático e participativo. No entanto, como mostra Paes-Paula (2005), o projeto político e a abertura à participação social de ambos os modelos se tornaram bem distintos:

Quadro 1: Projeto e Abertura Política dos Modelos de Administração

\begin{tabular}{|c|c|c|}
\hline Projeto político & $\begin{array}{c}\text { Administração Pública } \\
\text { Societal }\end{array}$ & $\begin{array}{c}\text { Administração Pública } \\
\text { Gerencial }\end{array}$ \\
\hline $\begin{array}{c}\text { Enfatiza a participação } \\
\text { social e procura estruturar } \\
\text { reprojeto político, que } \\
\text { desenvolvimento de } \\
\text { brasileiro, a estrutura do } \\
\text { aparelho de Estado e o } \\
\text { paradigma de gestão. }\end{array}$ & $\begin{array}{c}\text { Enfatiza a eficiência } \\
\text { administrativa e se baseia no } \\
\text { ajuste estrutural, nas } \\
\text { recomendações dos } \\
\text { organismos multilaterais } \\
\text { internacionais e no movimento } \\
\text { gerencialista. }\end{array}$ \\
\hline $\begin{array}{c}\text { Abertura das } \\
\text { instituições } \\
\text { políticas à } \\
\text { participação social }\end{array}$ & $\begin{array}{c}\text { Participativo no nível das } \\
\text { instituições, enfatizando a a } \\
\text { elaboração de estruturas e } \\
\text { canais que viabilizem a } \\
\text { participação social. }\end{array}$ & $\begin{array}{c}\text { Participativo no nível do } \\
\text { discurso, mas centralizador no } \\
\text { que se refere ao processo } \\
\text { decisório, à organização das } \\
\text { instituições políticas e à } \\
\text { construção de canais de } \\
\text { participação social. }\end{array}$ \\
\hline
\end{tabular}

Fonte: adaptado de Paes-Paula, 2005, p. 41.

Contudo, dada a reforma gerencial do Estado, em andamento nos anos de 1990 e a Constituição Federal de 1988 vigente, o país passou a conviver com um modelo administrativo dualista, sob a rearticulação do Estado pela combinação da democracia representativa com a participativa (SOUZA-SANTOS, 1999, apud PAES-PAULA, 2005). Partidos opostos à reforma gerencial aderiram às práticas do segundo modelo, ou seja, pela cogestão e participação dos cidadãos nas decisões sobre o encaminhamento governamental, principalmente, em governos municipais sob comando de partidos ideologicamente heterodoxos. Assim, a Administração Societal proporcionou experiências alternativas, de forma fragmentada, como por intermédio de Fóruns temáticos, Conselhos Gestores e Orçamento Participativo (PAES-PAULA, 2005). Enquanto isso, o modelo gerencial não apresentou eficácia no crescimento econômico por intermédio do centralismo decisório, seu foco principal.

Mesmo que a ampla maioria dos partidos tenha adotado a bandeira da democracia como forma de construção social, posteriormente à redemocratização do país, um regime democrático estaria condicionado à legitimidade de opiniões e complementariedade entre participação e representação nas decisões sobre políticas públicas, fato não logrado nas gestões nacionais. Muito embora tenha havido grande expectativa de movimentos organizados da sociedade civil, o modelo societal não se efetivou como marca do governo de Luiz Inácio Lula da Silva e de Dilma Rousseff (PAES-PAULA, 2005). O motivo das três derrotas de pleitos anteriores de Lula, causadas pela resistência de setores conservadores e liberais, foi neutralizado pela "Carta aos 
Brasileiros", em que o candidato se comprometeu a manter a política econômica vigente (CARVALHO, 2015). Tal compromisso, assumido por Lula em 2002, acarretou na permanência majoritária dos princípios do modelo de Administração Gerencial no país.

O Partido dos Trabalhadores desenvolveu diversas formas de democracia participativa pelo Brasil em municípios, ao longo dos anos de 1990, especialmente, com relação aos Conselhos Gestores e Orçamentos Participativos, mas não apresentou um plano de governo nacional alternativo em relação ao modelo gerencial, priorizando decisões centralizadas para cumprir os compromissos financeiros do país, lutar contra a fome e a pobreza e investir em infraestrutura. Por uma política econômica híbrida, tanto Lula quanto Dilma priorizou as premissas do modelo gerencial e eles não consolidaram a Administração Pública societal, dados os fatores político-econômicos, que induziram o governo à tomada de posicionamentos centralizados. Porém, embora o governo não tenha assumido a bandeira da participação da sociedade civil como projeto governamental, salvo na ampliação das conferências nacionais ${ }^{2}$, os canais participativos, como os Conselhos Gestores, continuaram dando frutos dispersos em nível municipal.

Nessa convivência entre uma Administração Gerencial, como forma de se ampliar a eficiência do Estado, e Administração Societal, como meio de incentivar a participação social, durante o governo de Dilma Rousseff, o marco regulatório da sociedade civil, estipulado pelo Decreto № 13.019, de 31 de julho de $2014^{3}$, foi derrubado pelo Congresso Nacional. Tal decreto pode ser visto como ensaio de Administração Societal como modelo de governo e como resposta às demandas da sociedade, feitas nas mobilizações sociais de julho de $2013^{4}$, composta por três narrativas: exclusão social, busca de democracia participativa e de políticas de inclusão social (SOUZA-SANTOS, 2014). Esta recusa do Congresso demonstrou os impasses que o país passa, em relação a um modelo ideal de Administração pública mais inclusivo, e refletiu a barreira advinda de setores políticos tradicionais em aceitar a incorporação da participação social nas decisões públicas.

Por outro lado, como visto, mesmo sem um marco regulatório, permanece vigente o texto constitucional e legislações, que regulamentam a participação da sociedade civil na Administração Pública, as quais possibilitam ensaios de Administração Societal. Entretanto, o modelo ainda não possui uma proposta de organização do aparelho do Estado como a gerencial, que apresenta estratégias no núcleo do Estado, fato que colabora com o insulamento de decisões e de práticas personalistas (CORTÊS, 2007). Por isso, é necessária uma reflexão sobre a efetivação do modelo pelas experiências já realizadas de participação no âmbito da Administração Pública, como no caso dos Conselhos Gestores, para viabilizá-lo como alternativa nacional ao modelo gerencial em decadência.

\section{Participação Social e Conselhos Gestores}

A forma de participação social no Brasil, atualmente vigente, tem seu berço no instante da redemocratização do país entre 1983 e 1988, com o movimento Diretas-Já ${ }^{5}$ e o estabelecimento de uma
Constituinte aberta às demandas dos movimentos e organizações sociais. Tais manifestações garantiram, no texto constitucional, a previsão de instituição de políticas públicas mais inclusivas e equitativas nas diversas áreas, como saúde, educação e assistência social, bem como da ampliação de sistemas institucionalizados com objetivo de ampliar o exercício da cidadania $^{6}$.

Por meio da redemocratização do país houve a recuperação dos direitos civis e políticos, que haviam sido perdidos, ao longo do período do Regime Militar. No entanto, os direitos políticos se reconstituíram, nos anos de 1990, sob enfoque conceitual da cidadania liberal, de acordo com os pressupostos do neoliberalismo. Tenório (1998, p. 18) evoca Habermas (1995) para explicar tal forma de cidadania, bem como a alternativa republicana:

O conceito de cidadão na perspectiva liberal é definido em função dos "direitos subjetivos que eles têm diante do Estado e dos demais cidadãos (...) em prol de seus interesses privados dentro dos limites estabelecidos pelas leis" (Habermas, 1995:40). Já sob o conceito republicano, o cidadão não é aquele que usa a liberdade só para desempenho como pessoa privada, mas tem na participação uma prática comum "cujo exercício é o que permite aos cidadãos se converterem no que querem ser: atores políticos responsáveis de uma comunidade de pessoas livres e iguais" (Habermas, 1995:41).

Tendo em vista o conceito republicano de cidadania, são em seus direitos políticos que os cidadãos podem expressar uma nova concepção de Estado, mediante a participação social, frente ao contexto histórico da hegemonia dominante, na construção de políticas públicas. Estas vistas por Rodrigues (2011, p. 13), como "o canal pelo qual os diversos grupos que compõem a sociedade cujos interesses, valores e objetivos são divergentes - tomam decisões coletivas, que condicionam o conjunto dessa sociedade". Dessa dorma, políticas públicas deveriam consistir em ações coletivas e não privativas de instâncias de poder dominante, visto que podem determinar o contexto social, a articulação das classes e o direcionamento do Estado.

A importância da participação nas políticas públicas, nas últimas décadas, com foco nos agentes tomadores de decisões, surge diante de duas conjunturas: as novas visões de políticas póskeynesianas, com as restrições de gastos e nível de intervenção do Estado, nas políticas econômicas e sociais, no contexto da mundialização e globalização do capital; e a estruturação democrática dos países de democracia recente, como os da América Latina, que ainda não conseguiram formar coalizões políticas capazes de promover a economia e a inclusão social. Este contexto define uma constante, que autores caracterizam como democracia híbrida, formada pelo paradoxo que envolve legitimidade jurídica com falta de legitimidade social.

A formulação de políticas públicas é dada pela relação entre a tríade: Estado, mercado e sociedade civil - embora o segundo possa ser incluído dentro do terceiro elemento. Por exemplo, órgãos empresariais buscam políticas públicas, que promovam a iniciativa privada, mas tal iniciativa costuma favorecer mais a classe dominante. Assim como também as políticas sociais buscadas por segmentos organizados da sociedade civil estariam sujeitas às limitações do Estado mínimo, advindas das políticas neoliberais dos anos de 1990. Diferentes sujeitos também interferem, 
decisivamente, na concentração de interesses materializados nas políticas públicas, em detrimento de políticas, que visam uma equidade e universalidade social maior, com base em interesses mais amplos, com destaque ao poder de influência de canais midiáticos. Aponta-se, então, que a incorporação de políticas públicas nas agendas governamentais estaria atrelada à capacidade política e ao poder de pressão de grupos sociais, mas que nem todos estes possuem vozes ou são ouvidos.

Com a implantação do modelo neoliberal, advindo dos países desenvolvidos, no momento de polarização da política brasileira dos anos de 1990, mais propensa às ideologias ortodoxas, marcante nos dois governos de FHC, González (2011, p. 48) cita a diferenciação da participação social como:

Quando criados por governos identificados com a esquerda, com discursos sobre a democracia participativa e o poder popular. Quando por governos conservadores e neoliberais, sob o signo da racionalidade administrativa e do papel da população na fiscalização do gasto público.

De acordo com Touraine (1996, p. 160), "a sociedade política deve ser o espaço da igualdade; portanto, a democracia tem como objetivo principal garantir a igualdade não só de direitos, mas também das oportunidades e limitar o quanto possível a desigualdade dos recursos". Com isso, o processo democrático exercido pelo sujeito tem embasamento no momento em que ele percebe o significado de exercer a sua cidadania. Daí a importância de o cidadão conquistar espaços participativos de decisões públicas, como um método contra hegemônico.

Com base na análise de Touraine a respeito da sociedade política, percebe-se a reconfiguração do Estado com a Administração Societal pela ampliação do cânone do exercício da cidadania. Com a democracia participativa, um novo Estado social é formado mediante a incorporação da sociedade civil, nos espaços decisórios do cenário político, no qual o cidadão pode participar da dinâmica das políticas públicas. Então, um sistema de democracia participativa reduz o modelo tradicional de governo, como núcleo decisivo da vida política, contudo, sem tirar deste a obrigação pelas demandas públicas, buscando nas relações entre sociedade política e sociedade civil uma nova configuração política-ideológica.

Outro ponto em relação ao arcabouço governamental brasileiro é a o sistema de Estado federativo, caracterizado por autonomia municipal e estadual, que leva a uma variedade de arranjos institucionais nas Leis Orgânicas, impactando em diversas experimentações participativas. Embora tal autonomia seja positiva, em se tratando da ampliação destas experiências, a União não foi capaz de consolidar, nacionalmente, um modelo para tal fim. Os partidos políticos seguem com ideologias políticas fragmentadas, formando coalizões variadas em municípios, Estados e União, nos quais muitas vezes, o carisma de um candidato destaca-se mais do que o programa de toda a coligação.

Genericamente, a sociedade civil conquistou aberturas participativas nas tomadas de decisões públicas, como prática do poder descentralizado instituído na Constituição Federal de 1988, possibilitando o desenvolvimento da Administração Pública Societal. Neste contexto, são os Conselhos Gestores de Políticas
Públicas espaços de articulação da pluralidade social no direcionamento político ideológico do Estado. Amparados por legislações, que enaltecem a participação social, os colegiados focam na tese de que o poder do povo seria determinante nas tomadas de decisões do Estado.

Os Conselhos Gestores fazem parte de um modelo de desenvolvimento implementado por todo o mundo, como forma de governança democrática, visando maior participação dos cidadãos, na busca de soluções para problemas públicos, bem como para o desenvolvimento político dos indivíduos (GOHN, 2006). Gohn (2006, p. 07) descreve que:

Leis orgânicas específicas passaram a regulamentar o direito
constitucional à participação por meio de conselhos deliberativos, de
composição paritária, entre representantes do poder executivo e de
instituições da Sociedade Civil. (...). Trata-se de um novo padrão de
relações entre Estado e sociedade, porque eles viabilizam a
participação de segmentos sociais na formulação de políticas
públicas sociais que possibilitam o acesso aos espaços nos quais
se tomam as decisões políticas.

Pesquisas apontam que os Conselhos, em destaque ao longo da história, foram o de Comuna de Paris (1871), primeira experiência de governo operário, os sovietes russos (1905), os Conselhos de Turim (1920) - objeto de pesquisa de Antônio Gramsci (GOHN, 2006) e os Conselhos iugoslavos (1950). Podem estes ser considerados como resultado das lutas e das demandas da sociedade civil, em favor dos interesses coletivos, pela busca de inserção de classes no cenário político. Através desta participação, a sociedade civil se insere na configuração da máquina Administrativa Pública e, como uma forma de aprendizagem, contribui para a concepção de um mundo mais igualitário.

No Brasil, as experiências se iniciam nos anos de 1960, desenvolvendo-se ao longo do século como: os criados pelo Poder Executivo para intervir com as organizações populares; os populares, organizados pela sociedade civil para mediar relações com o poder público; e os institucionalizados, fomentados por leis, como os Conselhos Gestores, posteriores à Constituição de 1988 (GOHN, 2006). Estes últimos objetivam criar espaços democráticos expoentes de encontro e diálogo sobre políticas públicas, entre diferentes sujeitos, como um exercício de cidadania, um dos pilares da Administração Societal.

Nesse contexto, os Conselhos Gestores são apresentados como espaços fecundos para o desenvolvimento, elaboração, controle, fiscalização e continuidade de políticas públicas, em que a inclusão da sociedade civil representa a ressignificação do processo de fazer política, bem como a efetivação dos direitos políticos dos cidadãos. Por meio deste vinculo associativo entre sociedade política e civil, visiona-se debates para buscas de soluções aos problemas públicos, inclusive com relação ao desenvolvimento econômico local, que reflete em frutos ao nacional. Assim, a sociedade civil pode vir a participar do desenho institucional público, a fim de garantir, que interesses coletivos, sejam manifestados na realidade local e na construção de um novo Estado social. Contudo, diante da força e influência do neoliberalismo, é primordial uma análise pragmática de tais 
colegiados, sendo esta realizada, em seu contexto, objetivando a real participação social desenvolvida dentro destes órgãos.

\section{Os Conselhos Gestores de Políticas Públicas na prática}

Ao longo dos anos que vão de 1990 a 2000, além de legislações específicas com foco na regulamentação dos espaços institucionais, diversos estudos foram realizados na tentativa de se levantar os resultados do arcabouço organizacional dos Conselhos Gestores de Políticas Públicas, com base em levantamento de experiências pelo Brasil. Resultados sintéticos são apresentados por autores, como: Gohn (2011), Luchmann (2008), Tatagiba (2005), Cortês (2007), Avritzer (2008), Cotta et al (2011), Gurgel e Justin (2013) e Escorel e Moreira (2008), os quais possibilitam uma análise sobre o andamento de tais órgãos, para comparação com os pressupostos dos modelos administrativos.

Basicamente, os Conselhos Gestores objetivam, em seus regulamentos, um espaço institucional formado por representantes do Poder Executivo e por representantes da sociedade civil, em um desenho institucional de partilha de poder. Estão os Conselhos Gestores constituídos legalmente em diversas áreas, como na saúde, amparados pela Lei ํㅜ 8142/1990, na assistência social, pela Lei no 8242/1991, e na educação, pela Lei 9.394/1996, além de estarem assentes em normativas regionais.

Entretanto, conforme assinala Escorel e Moreira (2008), embasando-se nos estudos de (Marmor, 1983) e Cortês (2007), a constituição dos canais participativos não é condição única para que haja a participação efetiva da sociedade civil, no processo de decisão sobre políticas públicas. A participação social está condicionada, também, à capacidade de mobilização e organização de grupos sociais, ou seja, requer a existência prévia de movimentos populares, sindicais e lideranças específicas, que engajem no espaço de representação junto ao Estado. Além disso, o processo participativo dos conselhos é condicionado, também, pela posição favorável ou não das autoridades em relação à participação (CORTÊS, 2007).

Em municípios de grande porte, a pressão realizada por movimentos organizados da sociedade civil e por partidos, ideologicamente, voltados à inclusão social nas decisões sobre políticas públicas influencia o perfil da Administração Governamental, independentemente, do perfil ideológico das autoridades eleitas. Por isso, municípios maiores apresentam uma configuração propícia para formação de grupos de pressão, que influenciam a composição dos conselhos. No entanto, a realidade dos municípios de pequeno porte é diferente, embora ainda seja escassa a disponibilidade de pesquisa teórica dentro de tal contexto. Algumas limitações à participação social, em pequenos municípios, podem ser apontadas pelos contextos desfavoráveis às mobilizações expressivas da sociedade civil e de seus movimentos organizados e pela presença do tradicionalismo político, com base nas relações econômicas baseadas em restritos segmentos explorados.

Cotta et al. (2011) realizaram um estudo, em 2006, junto aos conselheiros municipais de saúde de Teixeira-MG, município de pequeno porte. No levantamento, a respeito do perfil dos conselheiros empossados, constataram que a maioria possuía algum engajamento político anterior, como candidatura política, ou vínculo com o funcionalismo público, sendo indicados pelos próprios gestores públicos. Tal fato revelou um profundo desconhecimento, tanto dos gestores quanto da sociedade local, sobre os preceitos institucionais e legais, que regem a formação dos Conselhos Gestores. Nem mesmo havia a presença de algum representante dos usuários do sistema sanitário no colegiado. Percebe-se, então, que o patrimonialismo e o clientelismo, presentes nas raízes políticas, interferem diretamente na relação entre os grupos de interesses e governo (CARVALHEIRO et al., 1992, apud CORTÊS, 2007).

$\mathrm{Na}$ prática, independentemente do tamanho do município, os Conselhos enfrentam conflitos com relação à representação, interação e disputa de poder com os eleitos pelo sufrágio universal no impacto efetivo das decisões, que levam à subordinação destes órgãos ao Poder Executivo. Além da própria corrupção, que tem como uma de suas vertentes a falta de controle social em determinadas áreas públicas. Estudos de diversos autores nacionais, como Luchmann (2008) e Tatagiba (2005), confirmam a dicotomia entre Conselhos Gestores e Estado no que se refere à disputa de poder decisório. Para Gohn (2011), estes colegiados podem ser tanto ferramentas valiosas de gestão democrática participativa quanto estruturas formais, podendo implicar no avanço sociopolítico de grupos organizados ou estagnar o cenário político, monopolizado por indivíduos, que não representam as comunidades que os indicaram.

Gurgel e Justen (2013) realizaram uma pesquisa, em 2011, a respeito do funcionamento do Conselho Municipal de Saúde de Niterói, do Conselho Municipal de Assistência Social do Rio de Janeiro e o Conselho Estadual do Rio de Janeiro, por meio da qual concluíram que o perfil dos agentes públicos envolvidos tendia ao centralismo decisório, ao mesmo tempo em que os sujeitos, representantes de segmentos sociais, apresentaram alienação quanto aos assuntos das pautas de reuniões. Com relação aos Conselhos de Saúde, levantaram a ausência de participação de representantes do mercado, fato que os levou a defender a tese de Labra (2006 apud GURGEL \& JUSTEN, 2013) de que os prestadores privados buscam resolver os seus interesses, diretamente, com os gestores públicos.

A proporção de participantes representantes da sociedade civil e de órgãos públicos é diversa. $\mathrm{Na}$ área de assistência social, desenvolvimento rural e educação, a participação deve ser de forma paritária. Na área de saúde, metade do Conselho deve ser composto por seus usuários e a outra metade por prestadores de serviços e profissionais da saúde. Já na do trabalho, a composição é tripartite: trabalhadores, patrões e governo (CORTÊS, 2007). Entretanto, Tatagiba (2005) relata que parte dos representantes da sociedade civil, nos conselhos, possui algum cargo público. Isto, possivelmente, se deve ao fato das reuniões serem realizadas em horário de expediente comercial e ao pouco conhecimento da sociedade civil a respeito destes espaços institucionais, que minimizam a oportunidade de classes trabalhadoras de participar 
dos colegiados. Como consequência, a paridade subjetiva condiciona a discussão e a tomada de decisão aos interesses dos representantes governamentais.

Sob esse aspecto, a legitimidade de representação dos Conselhos é colocada em dúvida pelo seu caráter segmentar frente aos representantes eleitos pelo sufrágio universal, os quais determinam as legislações sobre os órgãos. Luchmann (2008, p. 88) aponta que os Conselhos, "por apresentarem especificidades e diferenças substantivas em relação ao modelo da representação eleitoral (e embora dele sofram vários impactos), desafiam novas abordagens acerca da democracia”. Há diversos limites e desafios aos Colegiados na promoção de um aprofundamento democrático, em destaque, quanto à relação entre participação e representação. Embora dado tal conflito, os Conselhos constituíram "um exército de conselheiros, o que inaugura novas formas de representação da sociedade civil junto ao campo institucional" (LUCHMANN, 2008, p. 89).

Gohn (2006) descreve também que o caráter deliberativo não garante aos colegiados a implementação efetiva daquilo que foi deliberado em assembleia, principalmente, quando os resultados desinteressam aos dominantes políticos. Isto quando o Conselho é deliberativo, pois algumas legislações os definem como apenas consultivos. Como consequência da transição de governos, algumas políticas públicas são descontinuadas por não serem de interesse do novo governante sem consulta aos Conselhos Gestores, que possuem segmentos organizados, que poderiam apresentar os interesses sociais pela continuidade ou não de determinadas políticas.

Outro fato é a inserção dos interesses dos movimentos organizados da sociedade civil e dos menos ou não organizados dentro dos Colegiados. Tatagiba (2005) aprofundou-se nos perfis dos conselheiros e aponta uma tendência a elitização da participação, que coloca em risco o espaço de democratização e a capacidade de configuração do aparato Estatal. A elitização condiciona as políticas públicas à priorização de interesse particulares, que determinam qual rua será asfaltada, qual região terá prioridade no transporte, qual escola receberá uma reforma, etc., sem verificar o cenário amplo das necessidades locais.

A fragmentação de interesses sociais, inclusos nos Conselhos, pode ser explicada pela ausência de transparência de informações sobre os próprios órgãos. Se até mesmo alguns conselheiros relatam, que desconhecem os seus regimentos (GURGEL \& JUSTEN, 2013), resta para a sociedade civil a completa ignorância em relação aos espaços institucionalizados de participação, quando as informações não são adequadamente divulgadas.

Os critérios de escolha da composição dos Conselhos também passam por questionamentos, conforme Luchmann (2008). Como reduzir a sociedade em organizações e segmentos sociais, quais segmentos são legítimos para atuar nos Colegiados e quais os critérios de escolha são algumas das questões. Contudo, as escolhas comumente já são estipuladas por leis, nas quais os segmentos com maior mobilização conquistam a representação de interesses sociais.

Em síntese, os Conselhos Gestores têm como objetivo a consolidação daquilo que se pode definir como prática da Administração Societal, embasados em um modelo de partilha de poder entre representantes de movimentos organizados da sociedade civil e do Estado, materializado na sociedade política. Por meio desta estrutura, seria possível um maior aprofundamento sobre busca de soluções para problemas públicos pelo engajamento social. Porém, os seus resultados práticos, de acordo com as constatações levantadas pelos autores ora expostos, revelam em suas disfunções fatos, que Ihes distanciam da prática da Administração Societal, de acordo com o quadro 2:

Quadro 2: Funções e Disfunções dos Conselhos Gestores

\begin{tabular}{|l|l|}
\hline \multicolumn{1}{|c|}{ Funções } & \multicolumn{1}{c|}{ Disfunções } \\
\hline $\begin{array}{l}\text { Descentralização do poder sobre decisões } \\
\text { públicas. }\end{array}$ & $\begin{array}{l}\text { Subordinação ao Poder Executivo, que } \\
\text { desenvolve as legislações pertinentes e } \\
\text { detêm o status do sufrágio universal. }\end{array}$ \\
\hline $\begin{array}{l}\text { Representação de interesses coletivos, } \\
\text { pela busca de espaço de classes no } \\
\text { cenário político. }\end{array}$ & $\begin{array}{l}\text { Detentores de cargos públicos ocupam } \\
\text { vagas de representatividade da } \\
\text { sociedade civil. }\end{array}$ \\
\hline $\begin{array}{l}\text { Governança democrática de políticas } \\
\text { públicas. }\end{array}$ & $\begin{array}{l}\text { Caráter deliberativo ausente ou } \\
\text { delimitado, focando-se mais no } \\
\text { processo de fiscalização de políticas } \\
\text { públicas implementadas. }\end{array}$ \\
\hline $\begin{array}{l}\text { Articulação entre a pluralidade social no } \\
\text { direcionamento político ideológico do } \\
\text { Estado. }\end{array}$ & $\begin{array}{l}\text { Elitização da participação e } \\
\text { representatividade segmentada. }\end{array}$ \\
\hline
\end{tabular}

Diferentemente da participação de cunho representativo assente nos Conselhos, o desenvolvimento de outras experiências de participação direta apresenta também a aplicação do modelo de Administração Pública Societal. Como a experiência de orçamento participativo de Porto Alegre/RS, desenvolvida em 1989, que despertou a atenção de diversos pesquisadores sobre participação na democracia brasileira, e fora referida por Souza-Santos (2014, p. 105) como uma "verdadeira administração popular, assente numa prática consolidada de democracia participativa". A característica peculiar do orçamento participativo em relação aos Conselhos Gestores é de que aquele possibilita uma abertura participativa maior aos cidadãos, os quais podem participar sem vínculo associativo.

Entretanto, assim como o sucesso do modelo de desenho institucional "de baixo para cima" do orçamento participativo, Avritzer (2008) demonstra a possibilidade de sucesso do modelo de partilha de poder dos Conselhos Gestores. O autor descreve que o Conselho de Saúde de Belo Horizonte, um dos mais antigos do país, criado em 1991, teve como episódio a eleição para a presidência de um representante da sociedade civil, fato que ocorre em outros Colegiados formados por movimentos sociais engajados com as atividades públicas. Já o de Porto Alegre, criado em 1992, não considera prestadores de serviços como representantes da sociedade civil, mas sim, apenas usuários dos serviços públicos. Em São Paulo, a criação do Conselho de saúde antecede a lei regulamentadora, criado em 1989 na gestão de Luiza Erundina, e possui composição paritária, modelo que se estendeu não apenas para outros Conselhos Municipais de Saúde, como também para outros segmentos. Este Conselho entrou em conflitos diversos com 
o governo de Paulo Maluf, entre 1993 e 2000, devido às políticas de privatização do governante, implicando na suspensão de recursos federais para o município (AVRITZER, 2008).

Com relação à transparência das informações e ampliação da visibilidade dos espaços de participação social, algumas inovações vinculadas ao uso de redes virtuais apresentaram, neste novo século, avanços significativos. Dentre elas, destaque para a implantação do Portal dos Conselhos, em alguns municípios brasileiros, como em Piracicaba-SP, lançado em 2012, em São José dos Pinhais-PR, criado em 2013, e em Curitiba-PR, lançado em 2015, entre outros. Os espaços virtuais buscam divulgar as legislações pertinentes dos Colegiados, as suas composições e as suas atas, assim como disponibilizar canais para contato com os conselheiros. Assim, quando efetivados, possibilitam a promoção da transparência e do fortalecimento da democracia participativa (CURITIBA, 2016).

Os Conselhos Gestores obtiveram alguns sucessos em relação aos pressupostos da Administração Pública Societal, especialmente, nos casos dos municípios acima apresentados. Entretanto, como já discutido, tais municípios de médio e de grande porte possuem uma militância mais fortalecida, capaz de impulsionar sucesso na ocupação dos espaços institucionais de partilha de poder ou de desenho institucional de baixo para cima. Em geral, dado que o país é majoritariamente formado por municípios de pequeno porte e não há um pleno engajamento social das massas, as disfunções ora apresentadas são características persistentes em suas diversas manifestações. Um fator positivo das legislações nacionais recentes é o condicionamento de transferência de recursos federais para as subnacionais à criação de Conselhos, induzindo o despertar local para a criação dos Colegiados.

As maiores dificuldades da consolidação dos Conselhos Gestores estão nos municípios de pequeno porte, ampla maioria do Brasil, como aquelas apresentadas por Cotta et al. (2011), em que são mantidas as relações arcaicas de poder. Mesmo considerando a obrigatoriedade legal de os municípios constituírem Conselhos em determinadas áreas, a simples existência legal dos espaços não garante a prática de participação social. Ao se considerar o objetivo de fortalecer a sociedade civil no rumo da história, os Conselhos passam por análises sobre a inserção dos sujeitos, no cenário político e sobre o impacto dos interesses da sociedade civil, na realidade política-ideológica. Embora apresentadas como forma de se romper com o monopólio de representação dos partidos políticos, a participação no modelo gerencial de Administração Pública se limita, basicamente, na fiscalização das políticas públicas já instituídas, centralmente, pelos governos eleitos.

Como aponta Souza-Santos (2014), diante da atual conjuntura política e frente as distinções ideológicas partidárias, cabe aos partidos heterodoxos adotar e transformar as suas principais propostas em políticas públicas para sobreviver, como a defesa da gestão democrática e participação social, fato não logrado plenamente pelo PT, quando no Governo Federal. No entanto, o papel da sociedade civil e de seus movimentos organizados também é primordial, não apenas na ocupação dos espaços institucionais, como também na busca de transformação destes espaços em práticas de Administração Societal. Enquanto tal bandeira não for defendida, em cada município brasileiro, nas relações sociais e por intermédio dos canais de comunicação, os Conselhos Gestores seguem com as suas disfunções apresentadas nesta pesquisa, funcionando muito mais como manutenção da prática da Administração Pública Gerencial do que como consolidação da Administração Societal.

\section{Considerações Finais}

As legislações que regulamentaram os Conselhos Gestores, ao longo dos anos de 1990 e 2000, demonstram que o modelo de Administração Societal conviveu em relativa harmonia com a modelo gerencial, especialmente, no que tange ao cumprimento da Constituição de 1988. Assim, o modelo de Administração Pública Gerencial, mesmo priorizando princípios neoliberais e adotando políticas multilaterais internacionais, não impediu iniciativas regulamentais de democracia participativa. Possivelmente, as legislações sobre o tema só foram desenvolvidas devido à Constituição de 1988, escrita em um momento de instabilidade política e de reconhecimento das forças das mobilizações sociais.

Contudo, na prática, a Administração Pública Gerencial do Governo Federal demonstrou despreparo em implementar e incentivar uma participação social mais homogênea ao país. Sob preceitos neoliberais, a cultura política da sociedade civil, durante o período, não conquistou grandes avanços, expressando ondas de mobilizações sociais sem consolidação de ações mais efetivas em espaços institucionais. Como consequência, os entes federativos adotaram experiências dispersas, como os Conselhos Gestores, que não obtiveram pleno sucesso da participação social.

Tendo em vista os insucessos da Administração Pública Gerencial em solucionar os problemas públicos, o modelo de Administração Societal pode ser idealizado como alternativa, mas a sua efetividade está atrelada a um projeto nacional de implementação. A relevância da ocupação de espaços institucionais pela sociedade civil é dada, quando se analisa a cadeia desenvolvida pela Administração Societal, que tende a direcionar o poder de baixo para cima, como no caso do orçamento participativo, ou de partilha de poder, como no caso dos Conselhos. Com o advento da representatividade social, organizada em espaços institucionais, visiona-se um modelo de partilha de poder desta junto dos representantes eleitos pelo sufrágio universal e dos profissionais públicos, na busca de solutivas para os problemas econômicos e sociais.

Conclui-se que os Conselhos Gestores, mesmo enfatizando as suas relevâncias no direcionamento de políticas públicas, ainda não conquistaram, plenamente, uma prática de Administração Pública Societal exitosa, aproximando-se mais ao atendimento das demandas do modelo gerencial. É de grande relevância que, para alternância disso, haja capacitação de gestores governamentais sobre a importância de se incentivar a democracia participativa, visto que a ampla maioria desconhece os princípios da participação 
social e institucionalizam espaços para mero cumprimento legal. $\mathrm{O}$ cidadão, em seu sentido republicano, também deve cumprir o seu papel de ocupar os espaços institucionais e de se engajar na vida pública, a fim de controlar a elitização presente nos colegiados, visto a baixa cultura política do Brasil. Enquanto não há um modelo nacional de Administração Societal, a sociedade civil deve fazer uso dos meios de elaboração, implementação e fiscalização das políticas públicas, de forma a realizar uma mudança estrutural endógena no país.

Muito embora a Administração Gerencial tenha buscado alternativas para combater os problemas advindos das disfunções da burocracia, este modelo nunca deixou de estar enraizado nos processos Administrativos Públicos e até mesmo nos privados. $\mathrm{Na}$ verdade, seus problemas se originaram das deficiências da sua efetivação nas organizações, pois considerando o conceito weberiano de burocracia e racionalização, o modelo burocrático possibilita compreensão e elaboração racional das formas de organização e gestão. Por isso, torna-se indispensável para a incorporação da burocracia nos princípios da Administração Societal, para se disciplinar e consolidar a gestão participativa no âmbito da gestão pública brasileira, sob pressupostos da cidadania republicana.

Enquanto a União não consolidar um modelo de Administração Pública Societal, para tal desenvolvimento, é necessário aplicar, efetivamente, o conceito de cidadania republicana no instante da participação nos municípios, visto que apenas a regulamentação de espaços institucionais não garante voz à sociedade civil. É preciso ainda mais do que isso; faz-se mister observar os perfis dos conselheiros e suas instâncias representativas, a paridade, a legitimidade perante os eleitos pelo sufrágio universal e a efetividade das decisões tomadas pelos colegiados. Estas iniciativas podem ser adotadas no combate às disfunções dos Conselhos ora apresentadas, para avanço destes órgãos como espaços de consolidação da Administração Societal nos distintos entes federativos do Brasil.

Por meio das reflexões apresentadas neste artigo e os conflitos na implementação de Conselhos apontados pelos autores citados, sugere-se $o$ desenvolvimento de pesquisas adicionais, que analisem os Colegiados, em suas diversas expressões. Especialmente, considerando-se que as características exemplificativas dos Colegiados, ora apresentadas, não têm como intenção servir de forma generalista. Tais pesquisas são pertinentes para visualizar a efetivação dos espaços participativos desenvolvidos pelo Brasil e para aperfeiçoar o modelo de Administração Pública Societal, na defesa de uma alternativa ao modelo gerencial incapaz de absorver a sociedade civil no âmbito de sua gestão. Também se apresenta a implementação das sugestões apontadas em espaços, que se apresentem propícios, como aqueles em que o gestor público possui uma conscientização da importância da participação social e nas quais há maior engajamento social e movimentos sociais organizados.

\section{Referências}

Avritzer, L. (2008, junho). Instituições participativas e desenho institucional: algumas consideraç̃̃es sobre a variação da participação no Brasil democrático. Opinião Pública, Campinas, vol. 14 n. 1, p. 43-64.

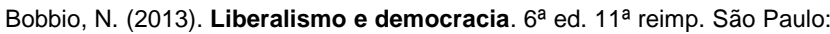
Brasiliense.

Bresser-pereira, L. C. (1977). O estado na economia brasileira. Ensaio de Opinião. Vol. 4, n. 2-2, p. 16-23.

Bresser-pereira, L. C. (1996, janeiro/abril). Da administração pública burocrática à gerencial. Revista do Serviço Público, n. 47(1).

Carvalho, J. M. (2015). Cidadania no Brasil: o longo caminho. 19 ed. Rio de Janeiro: Civilização Brasileira.

Cortês, S. V. (2007). Viabilizando a participação em conselhos de política pública municipais: arcabouço institucional, organização do movimento popular e policy communities. In: HOCHMAN, G et al. Políticas públicas no Brasil. Rio de Janeiro: Editora FIOCRUZ.

Cotta, R. M. M. et al. O controle social em cena: refletindo sobre a participação popular no contexto dos conselhos de saúde. Physis, Rio de Janeiro, v. 21, n. 3, p. 1121-1138, 2011. Disponível em: http://dx.doi.org/10.1590/S0103-73312011000300019. Acesso em 02 mar. 2017.

Curitiba. Prefeitura Municipal de Curitiba. Portal dos Conselhos. Disponível em http://www.curitiba.pr.gov.br/noticias/portal-da-maior-transparencia-aotrabalho-dos-46-conselhos-municipais-de-curitiba/35830. Acesso em $09 \mathrm{dez}$ 2016

Escorel, S; moreira, M. R (2008). Participação social. In: giovanella, Lígia (Org.). Políticas e Sistemas de Saúde no Brasil. Rio de Janeiro: Editora FIOCRUZ, p. 979-1010

Fernández, E. G. (2010) Novos instrumentos de participação: entre a participação e a deliberação. In SILVA, E. M.; CUNHA, E. S. M. (Orgs) Experiências internacionais de participação. São Paulo: Cortez. (Coleção Pensando a Democracia Participativa, v. 2).

Gohn, M. da G. (2006, janeiro/abril). Conselhos gestores e gestão pública. Ciências Sociais Unisinos, n. 42(1):5-11.

Gohn, M. da G. (2011). Conselhos gestores e participação sociopolítica $4^{a}$ ed. São Paulo: Cortez. (Coleções questões da nossa época; v. 32).

González, R. S (2011). Democracia, cultura política e experiências participativas na América Latina. In BAQUERO, M. (Org). Cultura(s) política(s) e democracia no século XXI na América Latina. Porto Alegre: Editora da UFRGS.

Gurgel, C.; JUSTEN, A. Controle social e políticas públicas: a experiência dos conselhos gestores. Rio de Janeiro: Rev. Adm. Pública, 47 (2): 357-378, mar./abr. 2013

Hirst, P. (1992). A Democracia Representativa e seus Limites. Rio de Janeiro: Jorge Zahar.

Luchmann, L. H (2008, janeiro/abril). Participação e representação nos conselhos gestores e no Orçamento Participativo. Caderno CRH, Salvador, v. 21 , n. 52 , p. $87-97$

Paes-paula, a. P (2005, janeiro/março). Administração pública brasileira entre o gerencialismo e a gestão social. Revista de Administração de Empresas, v. 45, n. 1.

Rodrigues, M. A. (2011). Políticas Públicas. São Paulo: Publifolha.

Souza-santos, B (2014). A cor do tempo quando foge: uma história do presente. Crônicas 1986 - 2013. São Paulo: Cortez.

Tatagiba, L (2005, novembro). Conselhos gestores de Políticas Públicas e Democracia Participativa: aprofundando o debate. Rev. Sociol. Polít. Curitiba, 25, p. 209-213.

Tenório, F (1998, setembro/outubro). Gestão social: uma perspectiva conceitual. Revista de Administração Pública, v. 32, n. 5, p. 7-23.

Touraine, A (1996). O que é Democracia? Petrópolis: Vozes.

modernos. Para o autor, o significado de democracia não se modificou na passagem dos antigos para os modernos, mantendo-se como "governo do
1 Considerar-se-á o conceito de democracia com base no estudo de Bobbio (2013, p. 31-32), que elenca a definição da democracia dos antigos e a dos 
povo, em contraposição ao governo de uns poucos". O que mudou foi o significado valorativo, passando o poder da democracia realizada, de forma direta, para uma democracia representativa, que seria a única forma possível de se governar em grandes Estados. Por isso, as formas diversas de democracia participativa e direta, em última instância, culminam na subordinação às decisões finais de representantes, que devem ouvir as vozes da sociedade civil em sua ampla composição.

${ }^{2}$ Realizadas a partir de 2003 , as conferências nacionais se apresentaram como uma forma institucionalizada de participação exitosa em temáticas como saúde, educação e assistência social, realizadas por etapas nos municípios, Estados e União, para discussão de políticas públicas setoriais. 3 Instituída em 23 de maio de 2014 por meio do Decreto presidencial no 8243 , pela presidente Dilma Rousseff, a PNPS estabelecia e regulamentava formas institucionalizadas de diálogo entre a sociedade civil e o Estado, constituindo mais um espaço participativo de expressão democrática.

${ }^{4}$ Desencadeadas pela organização do Movimento Passe Livre, as Jornadas de Junho reuniram milhares de pessoas nas ruas em todo o Brasil durante 0 mês de junho de 2013. Inicialmente, a pauta das reinvindicações era contra o aumento das tarifas do transporte público em São Paulo, mas em questão de dias, com o apoio da sociedade civil, as manifestações se expandiram para diversas cidades do Brasil, incorporando outras pautas como questões relacionadas ao combate à corrupção e melhorias na educação e na saúde pública.

${ }^{5}$ A campanha das Diretas-Já emergiu em 1984 em um momento de queda de credibilidade do Regime Militar instituído em 1964, gerando protestos populares por eleições diretas para presidente, promovida por sujeitos sociais e políticos.

${ }^{6}$ A cidadania é composta pelos direitos civis, políticos e sociais, conquistados nesta sequência na Inglaterra entre os séculos XVIII e XX (CARVALHO, 2015). No Brasil, segundo este autor, os direitos sociais se sobrepõem aos demais, pois houve uma inversão na conquista dos direitos, em especial, no momento do auge do Estado de Bem-Estar Social, que reduziu os direitos civis e políticos em prol dos sociais. Contudo, enquanto os direitos civis garantem a vida em sociedade, os direitos sociais a participação na riqueza coletiva, os direitos políticos garantem a participação social no Estado. 